\title{
Phototoxicity Study
}

National Cancer Institute

\section{Source}

National Cancer Institute. Phototoxicity Study. NCI Thesaurus. Code C116216.

A study of the effect of an agent on the skin or eyes, such that it induces a sensitivity to sunlight or other forms of light. 